\title{
SOBRE LA HABILIDAD DE UN ROGATARIO. DESAJUSTES Y CORRECCIONES EN LA PILA BAUTISMAL DE VILLUSTO (BURGOS)
}

\author{
ON THE SKILL OF A SCRIBE. \\ MISADJUSTMENTS AND CORRECTIONS ON \\ THE FONT AT VILLUSTO (BURGOS)
}

\author{
ALEJANDRO GARCÍA MORILLA \\ Universidad de León
}

Resumen: Es a través del análisis de las huellas dejadas en una inscripción donde podemos reconstruir su proceso de génesis y los problemas derivados de ella. Hoy analizamos la destreza del rogatario que ejecutó la inscripción de la pila bautismal de Villusto, donde veremos los errores que cometió y los recursos que utilizó para realizar las correcciones.

El método que hemos utilizado para analizar este proceso de elaboración de la inscripción es el expuesto por los profesores García Lobo y Martín López en su Introducción a la Epigrafia Medieval, desarrollado por García Lobo en La epigrafia medieval. Cuestiones de método y que es el que venimos utilizando para la edición del Corpus Inscriptionum Hispaniae Mediaevalium.

Todo ello para mostrar quién o quiénes fueron los autores materiales de la inscripción, su tradición y pericia y la relación entre los scriptoria librarios y epigráficos y los talleres escultóricos.

Palabras clave: Epigrafía medieval, Paleografía, inscripción, génesis, taller epigráfico.

Abstract: It is through the analysis of the traces left in an inscription that we can rebuild its genesis process as well as the problems derived from that genesis. Now we analyse the skill of a scribe who executed the inscription of the font at Villusto, where we shall see the errors he made and the resources he used to carry out the corrections.

The method followed to analyse this inscription elaboration process is the one accounted for by Professors García Lobo and Martín López in their Introducción a la Epigrafia Medieval (An introduction to Medieval Epigraphy), developed by García Lobo in La Epigrafía Medieval. Cuestiones del método (Medieval Epigraphy. Questions about its Meth$o d)$ and which is the one that has been used in the edition of Corpus Inscriptionum Hispaniae Mediaevalium.

The aim of all this is to show who was or were the real author(s) of the inscription, their background and expertise and the relationship between the scriptoria of books and epigraphs and the sculptor's workshops.

Key words: Medieval Epigraphy, Palaeography, inscription, genesis, Epigraphy workshop. 
Es cometido del estudioso de la escritura y de los objetos escritos analizar y explicar todos y cada uno de los fenómenos y peculiaridades, incluso los errores, que encuentre en esos objetos escritos. Detrás de cada uno de ellos encontrará una sociedad, un grupo, o una persona con circunstancias concretas que será responsable de esos objetos; falta de conocimientos o de habilidades profesionales, falta de atención o de interés, errores de cálculo, etc. pueden ser los factores que hayan propiciado esos fenómenos o esas peculiaridades ${ }^{1}$. Hacemos esta consideración previa porque el objeto escrito, todo objeto escrito debe responder a unos cánones concretos que, a su vez, variarán según los lugares y las épocas; todo lo que no responda a esos cánones tiene una explicación que, en última instancia, nos llevará hasta el responsable o responsables de la pieza. Cuando el objeto escrito es una inscripción - un letrero publicitario - los cánones a observar son muy concretos, por lo que se refiere tanto a su forma externa como a su forma interna. Y la persona, o personas, llamada a observar esos cánones va a ser el rogatario; va ser el encargado, profesional o simple conocedor, de materializar ese letrero.

En el Corpus de inscripciones medievales de la provincia de Burgos, tenemos una, actualmente conservada - aunque no precedente - en la iglesia de Santa María de Villusto ${ }^{2}$, cuyas peculiaridades se refieren a su aspecto externo, a la distribución más o menos armonioso del texto en el campo de escritura. Se trata de la Suscriptio del maestro Martín que termina los trabajos de una pila bautismal el año 1157. Dice así el texto:

Martinus me fecit, Era millesima centesima nonagesima quinta, regnante rex Aldefonsus imperator in Castella et in Leone et in Toleto et in Baeca et Almaria.

\footnotetext{
${ }^{1}$ Todos estos condicionantes se producen durante la génesis de le inscripción. Entendemos por génesis al estudio de los factores que intervienen en el proceso de elaboración de cualquier objeto escrito; es este caso, una inscripción. Estos tres factores son el autor, el destinatario y el rogatario. Cf. V. GARCÍA LOBO y Mª. E. MARTÍN LÓPEZ, De epigrafía medieval. Introducción y álbum, León 1995, p. 23, y V. GARCÍA LOBO, "La epigrafía medieval. Cuestiones de método", en Centenario de la cátedra de "Epigrafía y Numismática" Universidad Complutense de Madrid 1900/01-2000/01, Madrid 2001, pp. 88-89. Este proceso ha sido uno de los menos estudiados pero sin embargo más relevantes de la epigrafía. Cf. Ma. E. MARTÍN LÓPEZ, "Centros escriptorios epigráficos de la provincia de Palencia”, en De Litteris, manuscriptis, inscriptionibus. Festcshrift zum 65. Geburtstag von Walter Koch, herausgegeben von Theo Kölzer, Franz-Albrecht Bornschlegel, Christian Frield, Georg Vogeler, Wien 2007, p. 203.

${ }^{2}$ La localidad de Villusto se encuentra al norte de la ciudad de Burgos, muy próxima a Villadiego. Según buena parte de los historiadores, la pila perteneció a la desaparecida iglesia de San Martín (actual cementerio de la localidad) siendo trasladada posteriormente a la iglesia de Santa María, y conservándose en una dependencia anexa a la iglesia accesible desde el exterior. AA. VV. Enciclopedia del Románico en Castilla y León, Burgos I, Aguilar de Campoo, 2002, p. 669.
} 
Como vemos, alguien pone en boca de la pila bautismal que cierto Martínus la fabricó el año 1157, justamente cuando el emperador Alfonso VII reinaba en Castilla y León, y en Toledo, en Baeza y en Almería ${ }^{3}$.

El texto consta de la intitulación -Martinus - , el verbo notificativo - me fecit - y la data - Era... - , que en este caso va acompañada del sincronismo del reinado de Alfonso VII. Ateniéndonos al verbo notificativo podemos concretar que estamos ante una Roboratio o una Suscriptio. En el primer caso, Martín sería el comitente de la obra, quien la encarga — quien la mandó hacer ${ }^{4}$ - . En el segundo, se trataría del autor material de la pila bautismal ${ }^{5}$. Nosotros, sin embargo, nos inclinamos por esta última posibilidad. En otros ejemplos que tenemos de pilas bautismales románicas en la provincia, el comitente de la inscripción suele acompañar su nombre de algún apelativo alusivo a su dignidad eclesiástica (abbas, presbiter, etc.). Además, no son raros los casos en los que el artífice material firma la pieza. Aquí, además de artífices aparecen como autores de la inscripción, como emisores del mensaje publicitario, con una evidente intención propagandística.

\section{EL ROGATARIO Y LA CONSCRIPTIO.}

Sin embargo, a la hora de materializar un mensaje tan breve y sencillo, el rogatario, el supuesto profesional que llevó a cabo dicha materialización, cometió una serie de errores de cálculo que, como veremos, se distribuyen en los distintos momentos de la conscriptio epigráfica ${ }^{6}$.

\footnotetext{
${ }^{3}$ Garbiñe Bilbao llama la atención sobre la presencia de este mensaje conmemorativo de una batalla militar, que únicamente se repite en la pila bautismal de Terradillos de Sedano donde también se hace referencia al triunfo o soberanía militar de un monarca. Cf. G. BILBAO LÓPEZ, Iconografía de las pilas bautismales del románico castellano. Burgos y Palencia, Burgos 1996, pp. 253-254.

4 "Son inscripciones que dan la noticia del comitente de un edificio u objeto votivo cualquiera. [...] Equivalente a esta fórmula es fecit cuando es evidente que quiere significar lo hizo hacer". Cf. Ma. E. MARTÍN LÓPEZ y V. GARCÍA LOBO, "La epigrafía medieval en España. Por una tipología de las inscripciones", en VIII Jornadas Científicas sobre Documentación de la Hispania altomedieval (siglos VI-X), Madrid 2009, p. 193.

5 "Son las que dejan constancia del artífice de una pieza u obra. El verbo más frecuente es facere". Cf. Ma. E. MARTÍN LÓPEZ y V. GARCÍA LOBO, "La epigrafía medieval en España. Por una tipología...", p. 193.

${ }^{6}$ Entendemos por Conscriptio epigráfica a "la materialización del mensaje epigráfico", donde "podemos distinguir distintos momentos". Cf. V. GARCÍA LOBO y Ma . E. MARTÍN LÓPEZ, De epigrafia..., p. 28.
} 


\subsection{La minuta.}

La minuta es la anotación en pergamino, piedra o papel de los datos concretos de la inscripción. En nuestro caso, bien podría ser la simple anotación de la fecha de finalización de obra con el nombre de Martín como artífice ${ }^{7}$.

\subsection{Ingrossatio o mundum.}

Se trata de la ampliación de la minuta con todos los datos que deben aparecer en el texto epigráfico. Esta ampliación solía hacerse con la ayuda de formula$\operatorname{rios}^{8}$. En nuestro caso se eligió la conmemoración de un hecho relevante, respondiendo a una costumbre frecuente de completar las fechas con sincronismos históricos $^{9}$. La elección de un hecho de tan enorme importancia y la propia manera de hacerlo nos recuerda a la forma documental. Se trataría de perpetuar la memoria —universalidad y perdurabilidad de la inscripción — haciendo mención a un sincronismo con el que el rogatario estaba muy familiarizado.

\subsection{Ordinatio.}

Consiste en un conjunto de operaciones encaminadas a hacer una correcta traslación del texto a la superficie epigráfica en escritura publicitaria ${ }^{10}$. Está compuesta por tres fases: impaginación, preparación de espejo epigráfico y la transliteración del texto. Bajo nuestro punto de vista, es en esta fase en la que se produjeron esos desajustes que observamos en nuestra inscripción y que restan armonía y estética al conjunto escrito; nos referimos concretamente al acto de la impaginación y al de la transliteración del texto.

${ }^{7}$ Decimos esto porque en la provincia de Burgos hemos encontrado una minuta epigráfica esgrafiada en el ábaco de la columna del arranque del segundo arco de la izquierda de la portada de la ermita de Nuestra Señora del Torreón de Padilla de Abajo donde únicamente se consigna una fecha que coincide con la que porta el Monumentum primae petrae que se conserva en el interior. Así pues, debía ser una práctica habitual en la elaboración de minutas, a las que se les añadiría posteriormente el formulario al uso según su función.

${ }^{8}$ V. GARCÍA LOBO, "La epigrafía medieval. Cuestiones de método", p. 93.

${ }^{9}$ Así podemos verlo también en la Datatio de la burgalesa pila bautismal de Terradillos de Sedano: In Era millesima ducentesima quinquagesima, rex Castelle triunfavit super paganos. O en la Roboratio de la condesa doña Elvira Sánchez de Nogal de Huerta: (Christus) In nomine Domini nostro Ihesu Christi ob onore Sancti Salvatoris Ielvira Sansez hoc fecit in era millesima centesima prima regnante rex Ferdinando in Leione et in Kastella.

${ }^{10}$ V. GARCÍA LOBO y Mª. E. MARTÍN LÓPEZ, De epigrafía.., p. 29. 
La impaginación en esta inscripción casi parece no haberse previsto. Sin conservar líneas de pautado y sólo viendo cierta homogeneidad dentro de cada palabra, parece que ésta no se incluyó propiamente dentro de las tareas previas a la recepción de la escritura ${ }^{11}$. En la transliteración, el rogatario debía calcular la extensión del texto y adecuarlo uniformemente al espacio de que disponía. Sin embargo, observamos que la distribución del texto varía de principio a fin. Al inicio, diseñó letras de gran tamaño y bien separadas entre sí. Desarrolló las palabras por completo y únicamente en el numeral XL muestra una abreviatura que más que suponer un ahorro de espacio nos habla de una vinculación con la escritura visigótica cursiva ${ }^{12}$ :

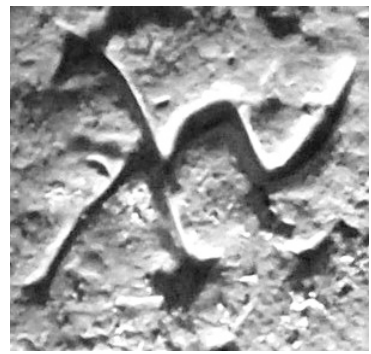

Fig. 1. Detalle X aspada de la data (García Morilla).

Sin embargo, en el momento en que consignan los estados del emperador, la tendencia se invierte. Es un proceso progresivo donde comienza a utilizar un repertorio de recursos de abreviación - propio de un profesional habituado a usarlas_-, que se acentúa en la parte central del texto como vemos en los diferentes detalles:

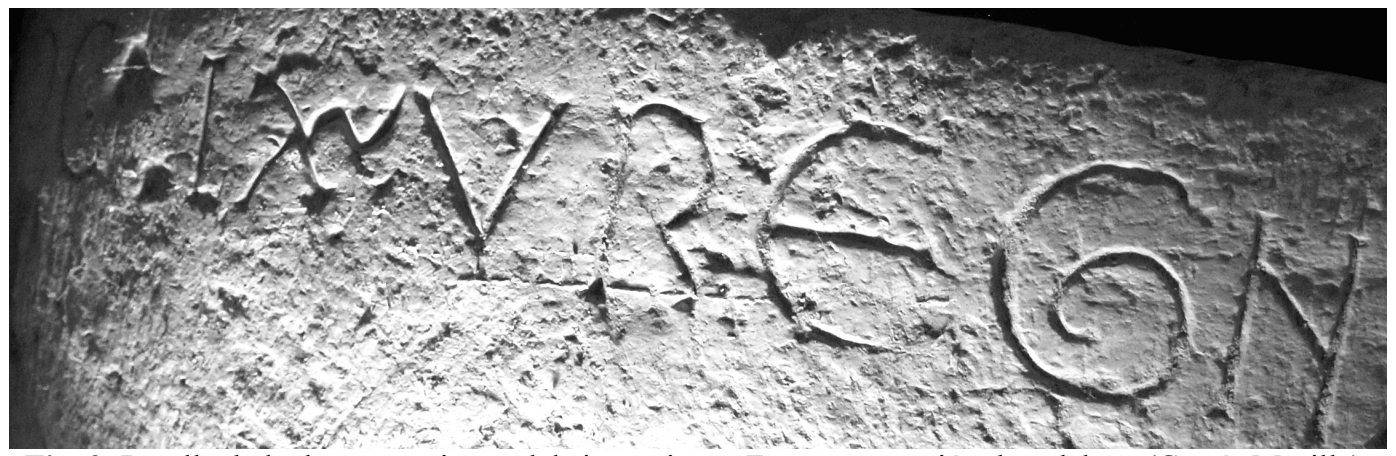

Fig. 2. Detalle de la data y comienzo del sincronismo. Fuerte separación de palabras (García Morilla).

${ }^{11}$ Sobre los diferentes tipos de impaginación remitimos a nuestro trabajo A. GARCÍA MORILLA, "La impaginatio en las inscripciones del románico burgalés", en Impaginatio en las inscripciones medievales, León 2011, pp. 213-229.

${ }^{12}$ Recordamos que la utilización de la $\mathrm{X}$ aspada es propia y exclusiva de la escritura visigótica. Su presencia en una inscripción en escritura carolina únicamente nos habla de la ascendencia y conocimiento del rogatario en una cultura escrituraria anterior. 


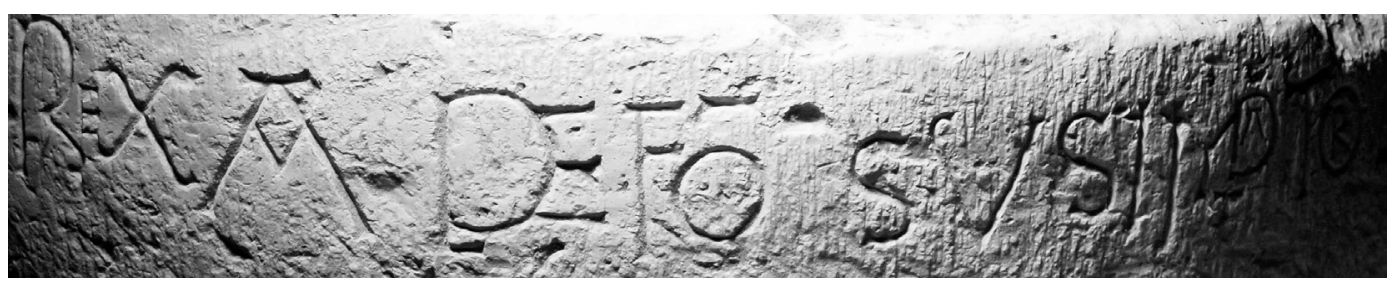

Fig. 3. Detalle del comienzo de la utilización de abreviaturas y nexos (García Morilla).

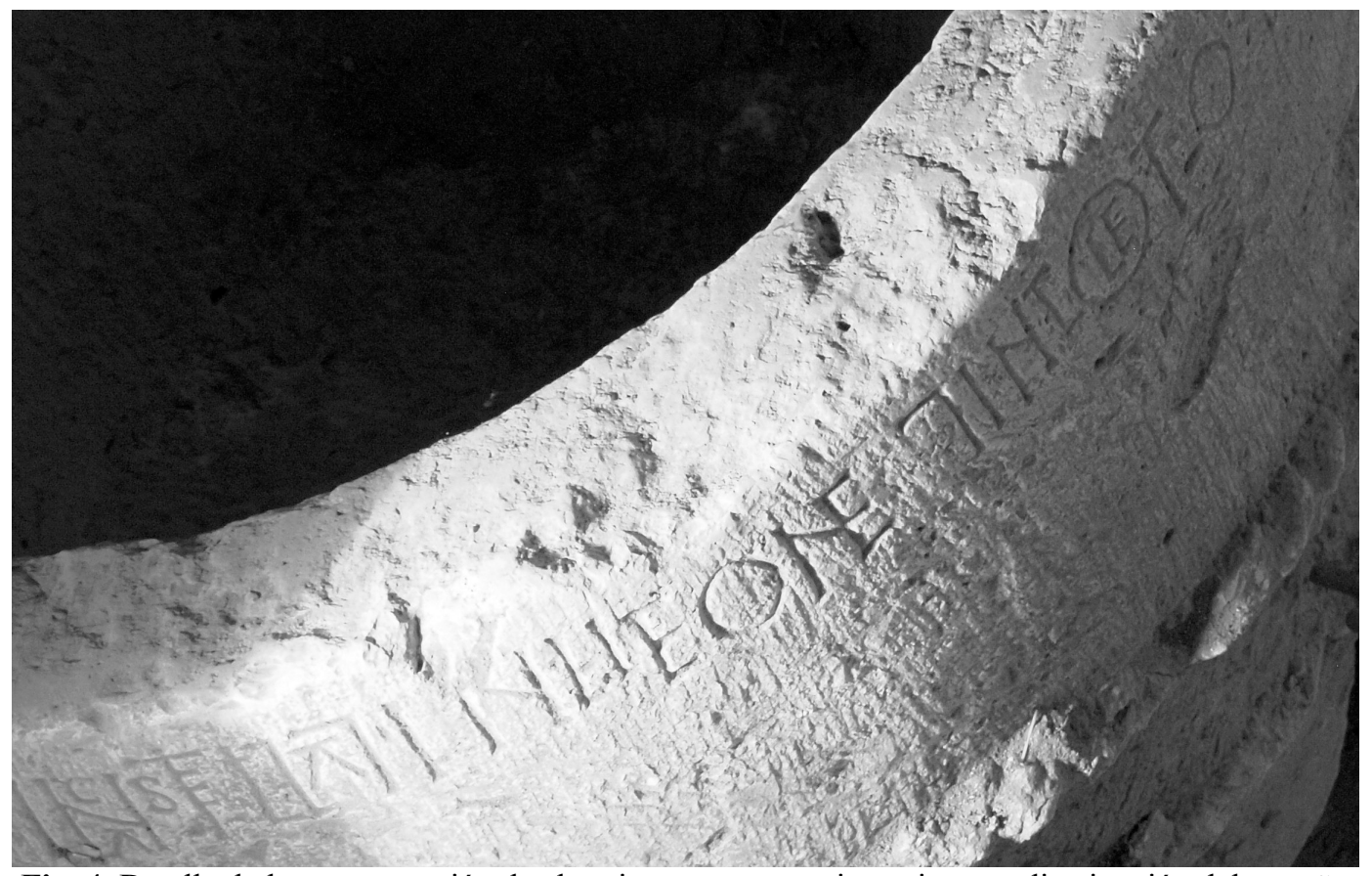

Fig. 4. Detalle de la concatenación de abreviaturas, nexos e inserciones y disminución del tamaño de las letras (García Morilla).

Es especialmente llamativa la utilización de la nota tironiana para abreviar et. Únicamente hemos encontrado este recurso en la provincia de Burgos en esta inscripción y en la Consecratio de la iglesia de Nuestra Señora de la Asunción de San Vicente del Valle, con el mismo objetivo de reducir espacio y cuadrar la inscripción dentro de la caja de escritura:

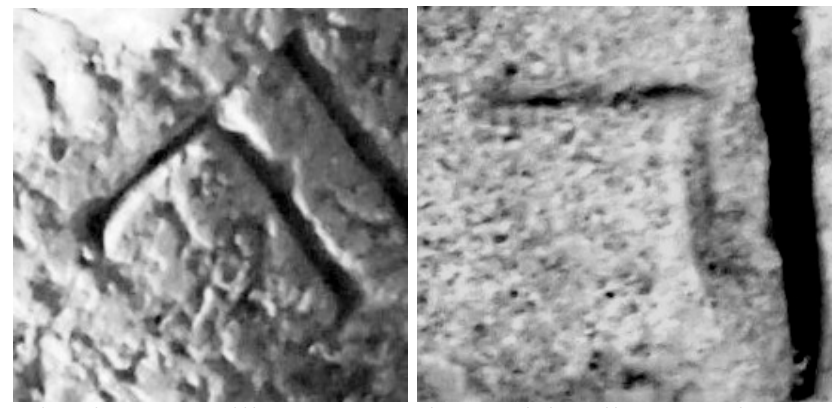

Fig. 5. Detalle notas tironianas en Villusto y San Vicente del Valle respectivamente (García Morilla). 
Al llegar al final del texto, es consciente de que aun tiene algo de espacio y vuelve a aumentar el tamaño de las letras y a prescindir de las abreviaturas:

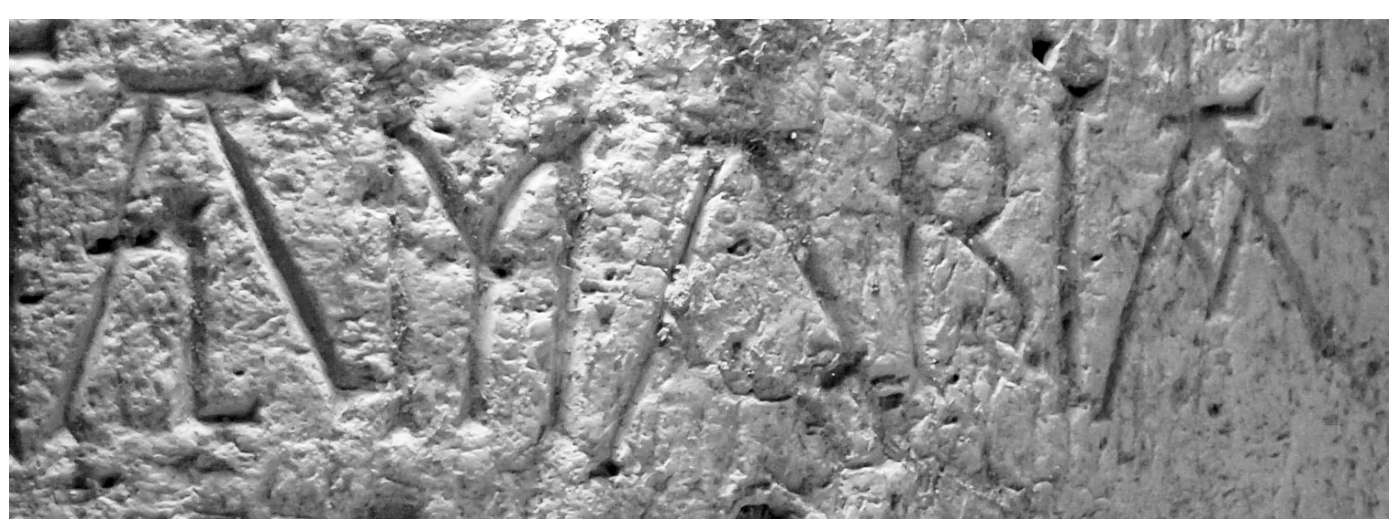

Fig. 6. Detalle de la última palabra del texto (García Morilla).

Como puede apreciarse en el detalle, además de ampliar el tamaño de las letras, la separación entre ellas también vuelve a ser acusada. Es especialmente llamativa la última A de la palabra, cuyo módulo es mucho más ancho que en el resto del texto. El motivo es alargar lo más posible la palabra para rellenar por completo el perímetro de la copa de la pila bautismal de forma que esta última palabra quede muy próxima de la $\mathbf{M}$ inicial de Martinus:

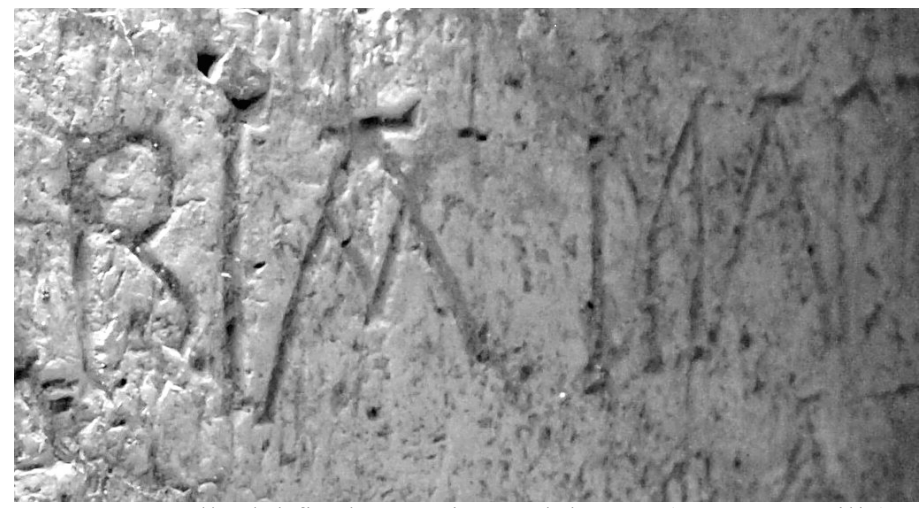

Fig. 7. Detalle del final y comienzo del texto (García Morilla).

\subsection{Incissio.}

Se trata del último paso en la materialización de la inscripción donde el texto es grabado "a base de martillo y cincel o punta seca"13. Este proceso no debió suponer grandes problemas a nuestro lapicida. Todo el texto se encuentra grabado

\footnotetext{
${ }^{13}$ V. GARCÍA LOBO, "La epigrafía medieval. Cuestiones de método", p. 95.
} 
mediante un surco de bastante profundidad. Es cierto que el ancho de cada línea del surco también varía de comienzo a fin, pero se trata de una necesidad lógica al tener que contraer el tamaño de letras y palabras:
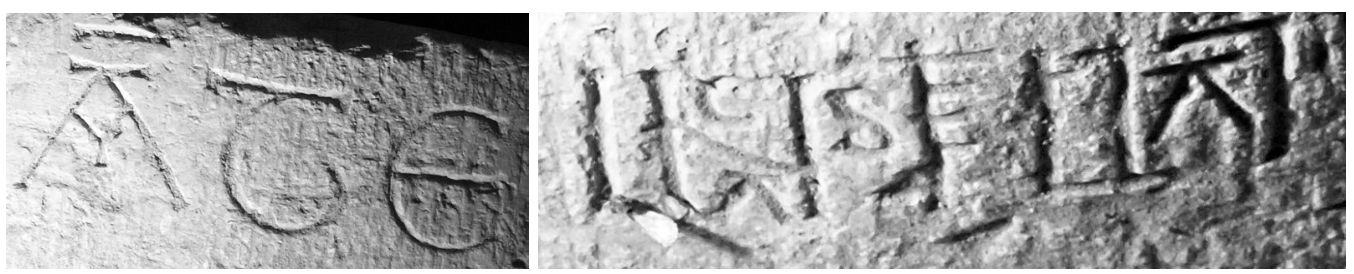

Fig. 8. Detalle del surco en el inicio y en la parte central de la inscripción (García Morilla).

Si unimos este análisis de la conscriptio de la inscripción con la propia elaboración de la pila bautismal nos encontramos con un conjunto rústico, toco, pero armónico. La única decoración que aparece es un motivo cordado alrededor de la copa, en recuerdo de las primitivas pilas bautismales de madera que utilizaban una o varias sogas para dar consistencia al conjunto ${ }^{14}$. Además, se trata del ejemplar datado más antiguo de pila bautismal del románico burgalés ${ }^{15}$; parece tratarse, por tanto, de una producción puntual ligada a un taller ocasional ${ }^{16}$.

Por otro lado, es evidente que el rogatario de la inscripción es conocedor de las técnicas gráficas; es conocedor de la escritura publicitaria y de las escrituras ordinarias tanto de códices como de documentos. Así lo refleja la utilización de la $\mathrm{X}$ aspada, la nota tironiana y las demás técnicas gráficas (nexos, inserciones y cruzamientos), y sobre todo, por la utilización del sincronismo del "regnante" que habla de la familiaridad de nuestro rogatario con la redacción de documentos. Así pues, nosotros pensamos que bien podía tratarse de un maestro artesano autor de la pila bautismal que contó con ayuda de un rogatario del scriptorium documental para la redacción y transliteración del texto epigráfico. También consideramos que la incissio o grabado final del texto corrió a cargo del propio Martín, más experto en el uso del martillo y del cincel.

\section{EL SINCRONISMO.}

No son frecuentes los sincronismos en las Datas de las inscripciones: la necesidad de concisión de los textos epigráficos pide que se rechacen. Así pues, cuando los encontramos deben responder a alguna circunstancia especial. Como

\footnotetext{
${ }^{14}$ G. BILBAO LÓPEZ, Iconografia..., p. 67.

15 AA.VV., Enciclopedia del Románico..., p. 671.

${ }^{16}$ Sobre los talleres epigráficos cf. $\mathrm{M}^{\mathrm{a}}$. E. MARTÍN LÓPEZ, “Centros escriptorios...”.
} 
decíamos anteriormente solo en otra pila bautismal burgalesa, la de Terradillos, encontramos un sincronismo similar. En este caso, se ensalza el triunfo del rey Alfonso sobre los paganos en clara alusión a la victoria cristiana en las Navas de Tolosa $^{17}$. Sin embargo, en Villusto el texto hace mención a la soberanía de Alfonso VIII en Castilla, en León, en Toledo, en Baeza y Almería, como Imperator Totius Hispaniae. Resulta harto difícil saber cual fue la motivación del autor para elegir este texto, aunque quizá haya que buscar la explicación en la repercusión que las conquista alfonsinas tenían en el viejo Condado de Castilla y/o al hábito del rogatario para la redacción de documentos de la época donde no pocos comenzarían con una intitulación similar al texto de nuestra pila.

De lo que no cabe duda es de que se trataba de un hecho conocido en el ambiente social de nuestro autor, ya que su elección implicaba la comprensión del texto por parte de los destinatarios directos en quienes estuviera pensando. Muy probablemente al tratarse de un hecho de tal magnitud, se garantizó la preservación de la memoria de la construcción de la pila bautismal. Ésta debía ser la principal inquietud de nuestro autor a la hora de incluir un sincronismo que diera mayor peso a los datos publicitados.

\section{EL TEXTO EPIGRÁFICO.}

1157

Suscriptio del maestro Martín en la pila bautismal de la iglesia de Santa María.

A. VILLUSTO, Iglesia de Santa María, Pila bautismal, inscripción en la parte superior. Escr. carolina de $6,5 \mathrm{~cm}$ x 3,5cm. No conserva líneas de pautado. Buen estado de conservación. Pieza de $389 \mathrm{~cm}$ x $11 \mathrm{~cm}$ aprox.

PUBL: Bilbao López, G., Iconografia, p. $254^{18}$; Enciclopedia del Románico, I, p. $671^{19}$.

${ }^{17}$ Recordamos el texto que dice: In Era millesima ducentesima quinquagesima, rex Castelle triunfavit super paganos.

${ }^{18}$ Garbiñe Bilbao, en la ficha final que realiza sobre cada una de las pilas bautismales hace referencia al emplazamiento de la misma diciendo que está en la Asunción de Nuestra Señora de Villusto. No sabemos si se trata de alguna advocación anterior popular, ya que en la documentación consultada siempre se hace referencia a las iglesias de Santa María y San Martín. Cf. G. BILBAO LÓPEZ, Iconografia..., p. 299.

${ }^{19}$ Los autores de la Enciclopedia del Románico transcriben directamente el nombre de BAEZA y de ALMERIA, no ajustándose al texto epigráfico que encontramos en la pila bautismal, que sí lee correctamente Garbiñe Bilbao. 


\section{MARTIN[US ME FECIT ERA] ${ }^{20}$ MCLXLV REGNĀNTE REX ADELFŎSVS IMP_ATOR IN CASTELLA ET IN LLEONE ET IN TOLETO ET IN BAEÇA ET İ ALMARIA}

Martin(us me fecit, Era) millesima centesima nonagesima quinta, regnante rex Adelfonsus imperator in Castella et in Leone et in Toleto et in Baeca et Almaria

Martín me hizo en el año mil ciento cincuenta y siete, durante el reinado del rey Alfonso ${ }^{21}$ emperador en Castilla y en León y en Toledo y en Baeza y Almeria.
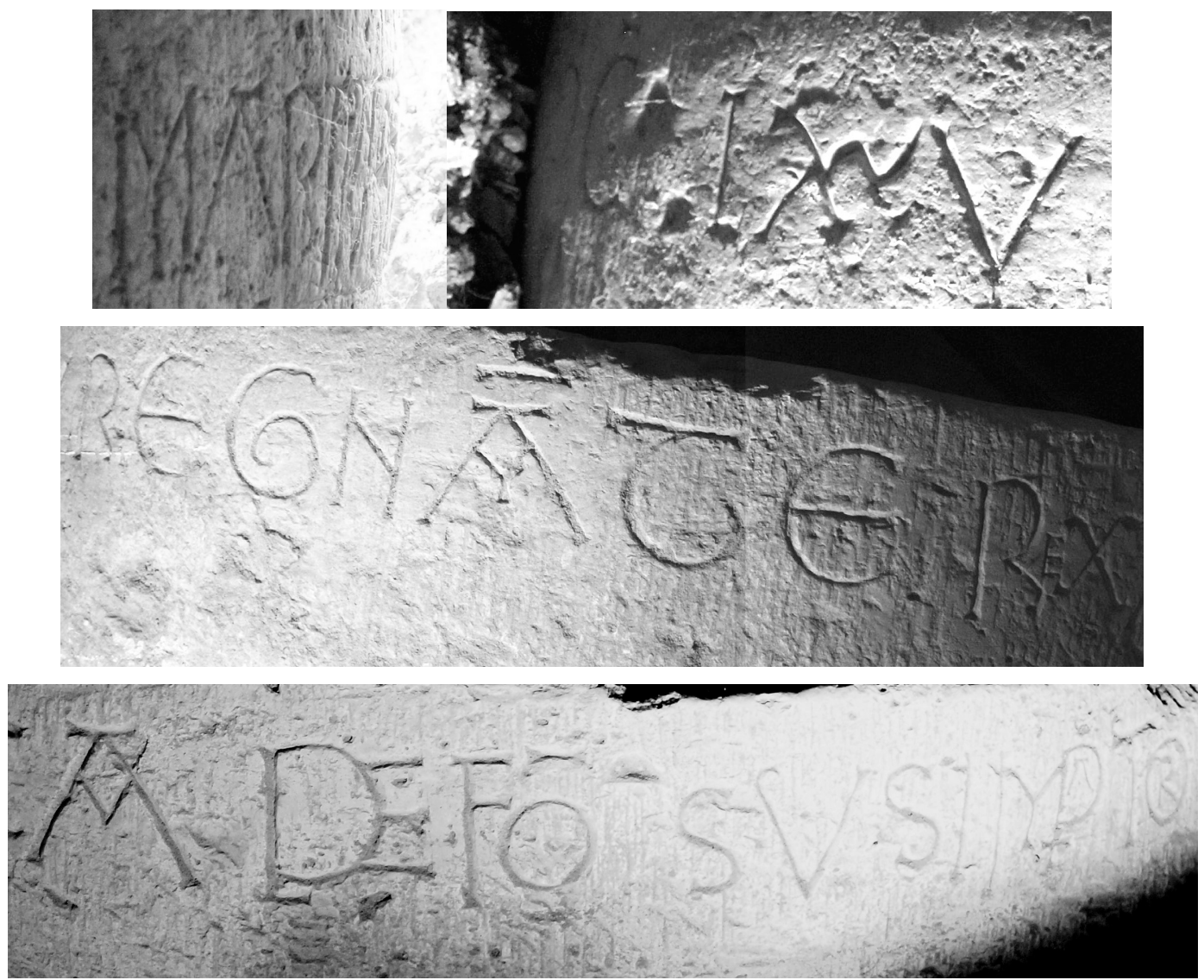

${ }^{20}$ Quizá, y por mayor lógica textual, deba incluirse dentro del texto no legible la palabra ERA para introducir la data.

${ }^{21}$ El texto hace referencia a Alfonso VII (1105-1157), rey de Castilla, de León, de Toledo y de Almería. Coronado en 1135 como Imperator Totius Hiapniae, recibiendo el homenaje del resto de soberanos cristianos. 
Alejandro García MORILla

SOBRE LA HABILIDAD DE UN ROGATARIO. DESAJUSTES Y CORRECCIONES EN LA PILA BAUTISMAL DE VILLUSTO
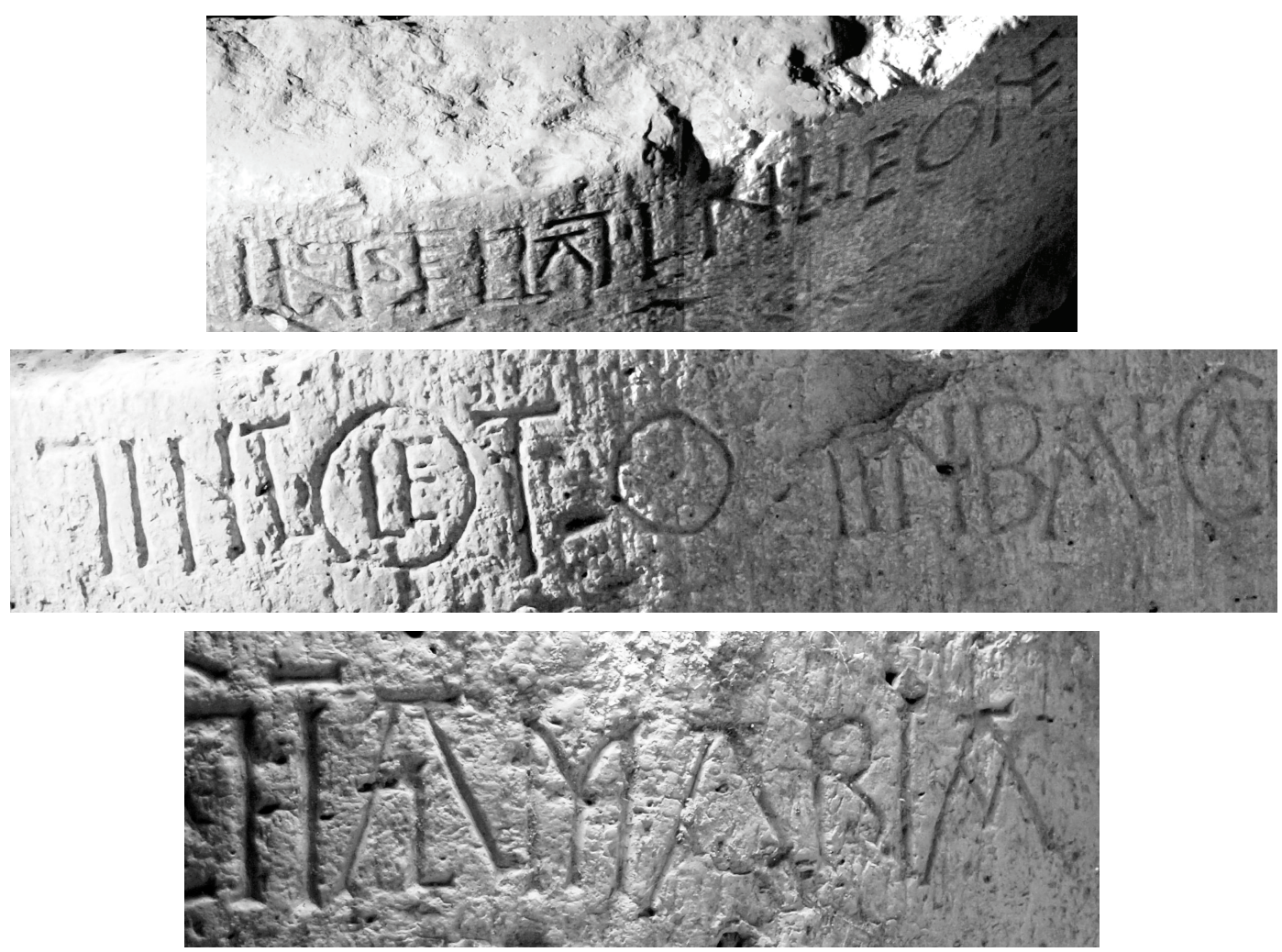